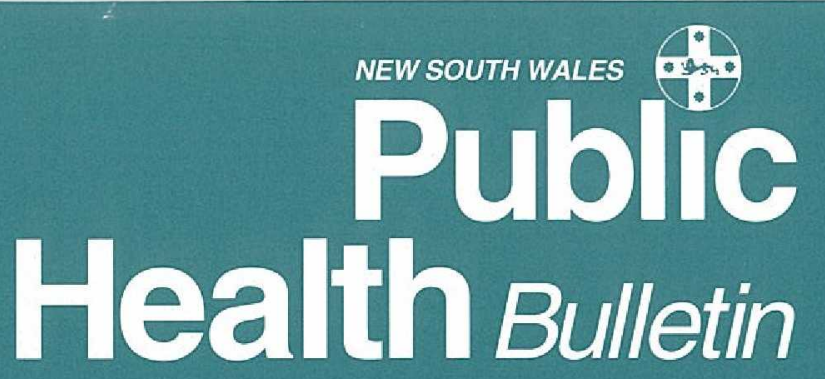

\section{HEALTH OF ABORIGINAL MOTHERS AND BABIES IN NSW}

Victoria Westley-Wise, Chronic Diseases Epidemiologist, Epidemiology and Health Services Evaluation Branch, NSW Health Department

Lee Taylor, Acting Manager, Maternal and Child Health, Epidemiology and Health Services Evaluation Branch, NSW Health Department

\section{SUMMARY}

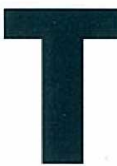

here are, on average, about 1,300 births to Aboriginal mothers in NSW each year - 1.5 per cent of all births in NSW. For Aboriginal mothers overall, pregnancy is characterised by fewer antenatal visits and higher rates of gestational diabetes, premature rupture of membranes and threatened premature labour compared with non-Aboriginal mothers. In 1982-90 the mortality rate among Aboriginal mothers was 47.3 per 100,000 births, which was 5.8 times higher than that of non-Aboriginal mothers. Aboriginal women are more likely to have a spontaneous onset of labour, and less likely to have an induction of labour, a forceps delivery or an elective caesarean section, than non-Aboriginal women. Aboriginal infants are more likely to be low birthweight or premature than non-Aboriginal infants, and are about twice as likely to die in the perinatal period.

\section{MethodologY}

Data were obtained from several sources: the NSW Midwives Data Collection (MDC), the NSW Inpatient Statistics Collection, the Registry of Births, Deaths and Marriages, notifications of maternal deaths to the NSW Health Department, and Australian Bureau of Statistics (ABS) census data for 1986 and 1991.

The NSW Midwives Data Collection covers all births in NSW of at least 20 weeks gestation or 400 grams birthweight. The MDC for the years 1986-88 and 1990-91 provided information on demography, pregnancy profile, labour and delivery, and infant characteristics. Unless otherwise specified, analyses refer to these five years. The MDC also provided information on perinatal deaths according to the type of delivery and the mother's number of previous pregnancies (parity). However, the perinatal mortality rates based on these data may be underestimates because the MDC form is completed before discharge or transfer of the infant, so some late neonatal deaths may not be recorded.

The NSW Inpatient Statistics Collection for the fiscal years 1989-90 and 1990-91 provided information on postpartum complications.

The NSW Registry of Births, Deaths and Marriages provided information on perinatal deaths (other than by type of delivery and parity) for the years 1987-1990. The perinatal mortality rates are based on year of birth, using Registry data for the numerator and MDC data for the denominator.

Aboriginal and non-Aboriginal resident populations as recorded by the ABS from the 1986 and 1991 Censuses were used as denominators to calculate fertility and crude birth rates. The resident population counts provided by the ABS for 1991 were preliminary.

Chi-square statistics were performed to test whether any apparent differences in proportions or rates between groups were statistically significant. A 5 per cent

\section{Contents}

\section{Articles}

1 Health of Aboriginal mothers and babies in NSW

4 Boom in demand for genetics services in NSW

6 The Australian Paediatric Surveillance Unit

\section{Public Healtb Abstracts}

\section{Infectious Diseases}

\section{Notifications}

10 Improving the quality of HIV data

\section{News and Comment}

\section{Correspondence}

Please address all correspondence and potential contributions to:

\section{The Editor,}

NSW Public Health Bulletin, Public Healtb Division, NSW Health Department Locked Bag No 961, North Sydney NSW 2059 Telephone: (02) 3919218 Facsimile: (O2) 3919232 


\section{Aboriginal mothers and babies}

\section{Continued from page 1}

significance level was used. Only differences which are statistically significant are reported as differences.

\section{DEMOGRAPHIC INFORMATION}

On average, 1,274 births of Aboriginal infants were reported to the MDC each year. This represents 1.5 per cent of all births in NSW. Eighteen per cent of Aboriginal women giving birth were resident in a Sydney Health Area, while 69 per cent were resident in a rural Health Region.

In 1991 the crude birth rate for Aborigines in NSW was 20.2 livebirths per 1,000 population, which was 1.3 times higher than for the non-Aboriginal population. The general fertility rate for Aboriginal women in 1986 was 84.2 livebirths per 1,000 women (aged 15-44 years), which was also 1.3 times higher than for non-Aboriginal women. The highest agespecific fertility rate for Aboriginal women was in the 20-24 years age group (142.9 livebirths per 1,000 women), followed by the 15-19 age group (92.0 livebirths per 1,000 women) (Figure 1). In contrast, for non-Aboriginal women the highest age-specific fertility rate was in the 25-29 age group (113.4 livebirths per 1,000 women).

Aboriginal mothers tended to be younger than nonAboriginal mothers: 27 per cent of Aboriginal women giving birth were teenagers compared with 5 per cent of nonAboriginal women. A higher proportion of Aboriginal women giving birth in the Regions were teenagers ( 30 per cent) than Aboriginal women resident in the Areas (20 per cent). There were higher proportions of Aboriginal teenage mothers in the Orana and Far West and New England Regions than Aboriginal mothers elsewhere in NSW.

Aboriginal women giving birth were more likely to be single than non-Aboriginal women: 56 per cent of Aboriginal mothers were single compared with 11 per cent of nonAboriginal mothers.

\section{PREGNANCY PROFILE}

Aboriginal women tended to be of higher parity (i.e. have had more previous pregnancies) than non-Aboriginal women: 5 per cent of Aboriginal women giving birth had at least five previous pregnancies, compared with 0.7 per cent of non-Aboriginal women. Thirty-four per cent of Aboriginal women gave birth for the first time, compared with 40 per cent of non-Aboriginal women.

Aboriginal women tend to have fewer antenatal visits than non-Aboriginal women: more than 6 per cent of Aboriginal women giving birth had fewer than two antenatal visits throughout their pregnancy in 1986-88 compared with less than 1 per cent of non-Aboriginal women.

Over the same period, 27 per cent of Aboriginal women had their first antenatal visit after 20 weeks gestation, compared with 11 per cent of non-Aboriginal women. Less than half (49 per cent) of Aboriginal women had their first visit within the first trimester (12 weeks), compared with about two-thirds (65 per cent) of non-Aboriginal women.

The proportion of Aboriginal women having fewer than two antenatal visits during their pregnancy was higher:

for young women (10 per cent of women aged less than 17 years compared with 4 per cent of women aged 30 years and above);
FIGURE 1

AGE-SPECIFIC FERTILITY RATES BY ABORIGINALITY, NSW 1986

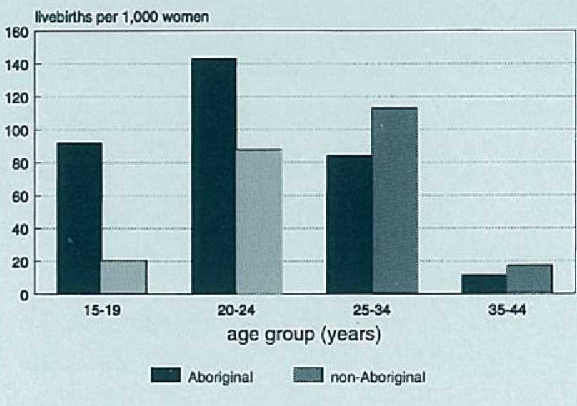

口 $\quad$ in Sydney Areas compared with Regions (9 per cent compared with 6 per cent); and

- in the Central Sydney Area (12 per cent) compared with elsewhere in NSW.

For the period 1986-88, general practitioners (GPs) were most commonly responsible for the antenatal care of Aboriginal women in the Regions, and public hospitals were most commonly responsible for their antenatal care in the Areas. Overall, GPs were the single most frequent provider of antenatal care for Aboriginal women, being responsible for the antenatal care of 50 per cent of Aboriginal women, compared with 19 per cent of non-Aboriginal women. Aboriginal women - in both the Areas and Regions - were much less likely than non-Aboriginal women to have antenatal care provided by specialist obstetricians ( 21 per cent compared with 53 per cent).

The rate of gestational diabetes in 1990-91 for Aboriginal women was 15.4 per 1,000 confinements, which was 1.4 times higher than for non-Aboriginal women. The rates of premature rupture of membranes and threatened premature labour for Aboriginal women in 1986-91 were 22.9 and 21.4 per 1,000 confinements, respectively, which were both 1.5 times higher than for non-Aboriginal women.

Over the period 1982-90 five deaths of Aboriginal women were reported to the NSW Health Department which were directly or indirectly attributable to pregnancy or its management. This represents a maternal mortality rate of 47.3 per 100,000 births, which was 5.8 times higher than the rate for non-Aboriginal women. The rate for direct maternal deaths in Aboriginal women was 37.9 per 100,000 births, which was 7.4 times higher than for non-Aboriginal women.

\section{LABOUR AND DELIVERY}

Ten per cent of Aboriginal women giving birth were confined in Level 6 (special obstetric) hospitals, 62 per cent were confined in Level 4-5 (country base/metropolitan district) hospitals and 27 per cent were confined in Level 1-3 (local, small isolated and country district) hospitals. Aboriginal women were less likely than non-Aboriginal women to be confined in Level 6 and Level 4 hospitals, and more likely to be confined in Level 5, Level 3 and Level 2 hospitals.

The onset of labour was spontaneous for 80 per cent of Aboriginal births and induced for 14 per cent of Aboriginal births. Aboriginal women were more likely to have a spontaneous onset of labour and less likely to have an induction of labour than non-Aboriginal women. 


\section{FIGURE 2}

BIRTHWEIGHT BY ABORIGINALITY, NSW 1986-91

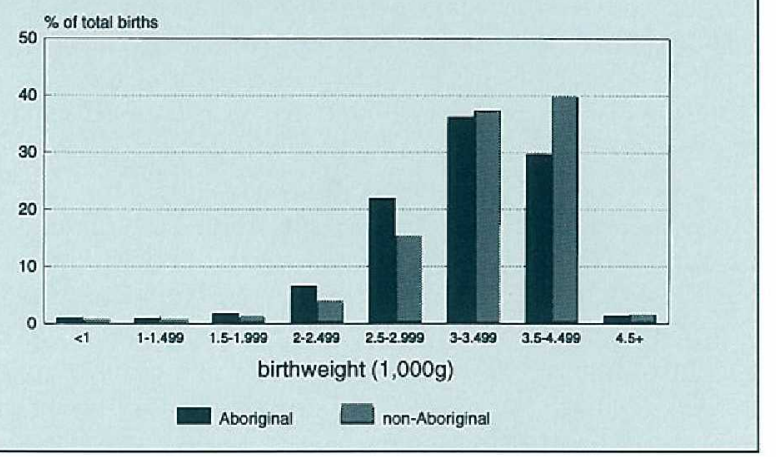

Seventy-seven per cent of Aboriginal births were by spontaneous cephalic delivery, 7 per cent were delivered by forceps and 14 per cent were delivered by caesarean sections (elective: 6 per cent, emergency: 8 per cent). Overall, there were no significant differences in types of delivery of Aboriginal infants between the Areas and Regions. However, compared with non-Aborigines, Aboriginal infants were more likely to have spontaneous cephalic deliveries, and less likely to be delivered by forceps and elective caesarean sections. That Aboriginal women were of higher average parity than non-Aboriginal women does not explain the differences in type of delivery between the two groups.

Breech presentations were less common for Aboriginal births than non-Aboriginal births, the rates being 33.9 and 43.4 per 1,000 births respectively. Aboriginal births with breech presentations, however, were more likely to have a vaginal delivery than non-Aboriginal births.

The rate of major puerperal infection for Aboriginal women in 1989-90 and $1990-91$ was 11.8 per 1,000 confinements, which was nearly four times higher than for non-Aboriginal women.

\section{INFANT CHARACTERISTICS}

The birthweight distribution of Aboriginal infants is skewed towards lower birthweights compared with non-Aboriginal infants (Figure 2). Ten per cent of Aboriginal births were of low birthweight (less than 2,500 grams), which was 1.8 times higher than for non-Aboriginal infants.

The gestational age distribution of Aboriginal infants is also skewed towards lower gestational ages compared with nonAboriginal infants. Ten per cent of Aboriginal births were premature (less than 37 weeks gestation), which was 1.4 times higher than for non-Aboriginal births.

More than 4 per cent of Aboriginal infants were born at term but of low birthweight (i.e. at least 37 weeks gestation but less than 2,500 grams), which was 2.1 times higher than for non-Aboriginal births.

The majority of both Aboriginal (58 per cent) and nonAboriginal (65 per cent) low birthweight infants were premature (rather than term low birthweight) births.

The risk of low birthweight for Aboriginal infants was highest for:

\section{FIGURE 3}

LOW BIRTHWEIGHT BY ABORIGINALITY AND ANTENATAL VISITS, NSW 1986-88

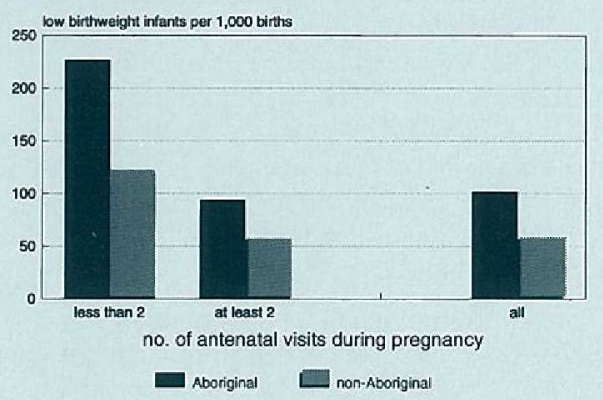

- women having their first child (12 per cent);

- women who had at least five previous pregnancies (13 per cent); and

- women who had fewer than two antenatal visits during their pregnancy (23 per cent) (Figure 3).

The risk of prematurity for Aboriginal births was highest for:

- teenage mothers (12 per cent);

- mothers aged 40 years and above (12 per cent); - women having their first child (11 per cent); and - women who had fewer than two antenatal visits during their pregnancy (21 per cent).

The rates of low birthweight, prematurity and term low birthweight for Aboriginal births were higher than for nonAboriginal births, even after differences in maternal age and parity and number of antenatal visits were taken into account. This suggests that differences in these factors between Aboriginal and non-Aboriginal mothers, alone, cannot adequately explain the excess risk of poor perinatal outcomes for Aboriginal infants. For example, Figure 3 shows that the risk of low birthweight for infants born to women who had had fewer than two antenatal visits during their pregnancy was about two times higher for Aboriginal than non-Aboriginal infants.

\section{PERINATAL MORTALITY}

In 1987-90 there were 120 perinatal deaths among Aboriginal births, of which 75 ( 63 per cent) died before delivery (stillbirths), and 45 ( 37 per cent) died within 28 days of birth (neonatal deaths). This represents a perinatal mortality rate of 23.5 per 1,000 births, which was 1.9 times higher than for non-Aboriginal births. The stillbirth rate for Aboriginal infants was 14.7 per 1,000 and the neonatal death rate was 8.8 per 1,000 , which were 2.0 and 1.8 times higher respectively than for non-Aboriginal births. Overall, the perinatal death rates for Aboriginal infants were not significantly different between the Areas and Regions.

The risk of perinatal death is higher for infants with lower birthweights. Fifteen per cent of Aboriginal low birthweight infants died in the perinatal period, which was the same proportion as for non-Aboriginal low birthweight infants. This suggests that much of the excess risk of perinatal death for Aboriginal infants is due to the fact that Aboriginal infants are more likely to be born with a low birthweight. 


\section{BOOM IN DEMAND FOR GENETICS SERVICES IN NSW}

Jennifer Blackwell, Executive Officer, NSW Genetics Service, NSW Health Department

G enetic disorders and birth defects impose a heavy physical, emotional and financial burden on individuals, families and the community. Advances in science and technology are expanding knowledge of the role of genes in disease and are leading to better methods of preventing, diagnosing and treating genetic disorders and diseases of multiple causes, including genetic factors. Developments in screening programs, prenatal diagnosis and community education are increasing the availability of, and demand for, genetics services.

A major challenge is to implement new genetic technology in the most beneficial way, to ensure high-quality care and to ensure access to services. A new five-year plan, 1993 1998 , provides a framework for the ethical and effective development of genetics services until 1998. Maintaining the principle of an integrated approach encompassing clinical, counselling, educational and laboratory services centrally coordinated through the NSW Genetics Service Advisory Committee - is seen as the most effective and economical way of achieving the goals of the NSW Genetics Service. The major goals include:

口 ensuring the provision of, and access to, genetics services appropriate to the needs of the people of NSW; improving the use of information and services
relating to genetic disorders and birth defects; and reducing the impact of genetic disorders and birth defects on the sufferers, individuals at risk and their families.

Genes contain the information that determines how we grow, what we look like and how well our bodies work. Information in a gene is called the genetic code. Genes are part of chromosomes which are in all the cells of our bodies. We each have 46 chromosomes which contain between 50,000 and 100,000 genes. Chromosomes and genes are made of DNA. Our body's health and growth will be changed if the genetic code is changed or if there are extra or missing genes.

There has been an explosion of knowledge about the processes of heredity and their implications for human health. The international Human Genome Project aims to identify all the 50,000 to 100,000 genes in humans by the year 2005 .

Using both molecular biology techniques and family studies, nearly 5,000 disorders have been identified as being caused by a mutation in a single gene. The number of disorders susceptible to molecular genetic or DNA diagnosis is rapidly increasing. In recent months, genes have been located for Huntington disease, motor neurone disease, melanoma and osteoporosis.

Many medical problems evident at birth, or soon after birth, are primarily genetic in origin or include a genetic factor. Other genetic disorders appear later in life. Genetic disorders include: Down's syndrome, neural tube defect, cystic fibrosis, diabetes, fragile $\mathrm{X}$ syndrome, muscular dystrophies, spinal muscular atrophies, haemophilia, hearing disorders, neurofibromatosis, polycystic kidney disease, thalassaemias, phenylketonuria, galactosaemia and Huntington disease.

They also include some forms of heart disease, cancer, asthma, epilepsy, visual disorders, short stature syndromes, intellectual disability and hypothyroidism.

\section{Aboriginal mothers and babies}

\section{$\checkmark$ Continued from page 3}

The risk of perinatal death is higher for infants born prematurely. Seventeen per cent of Aboriginal infants born prematurely died in the perinatal period. This was 1.4 times higher than for non-Aboriginal premature births. However, excluding infants born at less than 25 weeks gestation, Aboriginal preterm births were no more at risk of perinatal death than non-Aboriginal preterm births. This suggests that at least some of the excess risk of perinatal death for Aboriginal infants is due to the fact that Aboriginal infants are more likely to be born prematurely.

The risk of perinatal death for Aboriginal births was highest for teenage mothers (30.3 per 1,000 births) (Figure 4), women having their first child ( 34.0 per 1,000 births), and vaginal breech deliveries (310.3 per 1,000 births).

Extreme prematurity was the single most common cause of perinatal death for Aboriginal infants, accounting for 19 per cent of perinatal deaths. In contrast, extreme prematurity accounted for 12 per cent of non-Aboriginal perinatal deaths. The rate of perinatal death due to extreme prematurity for Aboriginal births was 4.5 per 1,000 births, which was 3.0 times higher than for non-Aboriginal births.

'Maternal conditions which may be unrelated to pregnancy' were associated with 17 per cent of Aboriginal and 10 per cent of non-Aboriginal perinatal deaths. Most of these maternal conditions were hypertensive disorders (high

\section{FIGURE 4}

PERINATAL MORTALTTY BY ABORIGINALITY AND MATERNAL AGE, NSW 1987-90

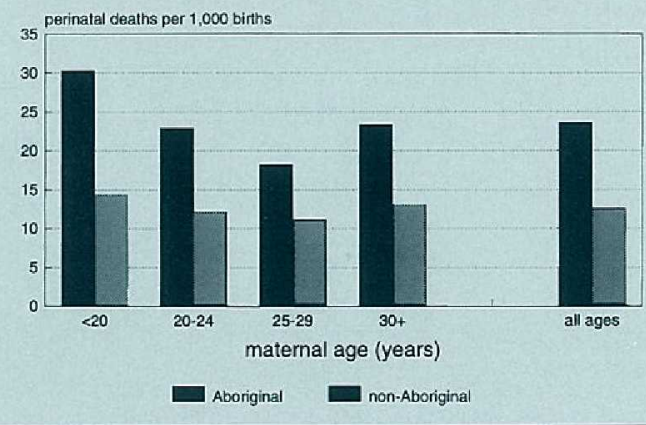

blood pressure). The perinatal death rate associated with maternal hypertensive disorders for Aboriginal births was 2.2 per 1,000 births, which was 3.1 times higher than for non-Aboriginal births.

'Other placental separation and haemorrhage' (i.e. other than placenta praevia) and 'other and unspecified morphological and functional abnormalities of the placenta' were both associated with 12 per cent of Aboriginal perinatal deaths. The perinatal death rates associated with these conditions for Aboriginal births were 2.1 and 3.6 times higher, respectively, than for non-Aboriginal births. 